REVISTA DE GESTAOD ESECRETARAADO

MANAGEMENT AND ADMINISTRATIVE

PROFESSIONAL REVIEW
Organização: SINSESP

Editora Científica: Dra. Cibele B. Martins

Avaliação: Double Blind Review pelo SEER/OJS

Revisão: Gramatical, normativa e de formatação

Data de recebimento do artigo: $28-9-2017$

Data de aceite do artigo: 22-1-2018

DOI: http://dx.doi.org/10.7769/gesec.v9i1.723

\title{
Políticas públicas para agricultura familiar no interior do estado do Amazonas
}

\author{
Bruno dos Santos Rodrigues \\ Bacharel em Administração pela Universidade Federal do Amazonas (UFAM). E-mail: \\ bruno94.58@hotmail.com (Brasil) \\ Frâncio Costa Simão \\ Bacharel em Administração pela Universidade Federal do Amazonas (UFAM). \\ E-mail: francio.costa@hotmail.com (Brasil)
}

Jonas Fernando Petry

Doutor em Administração pela Fundação Regional de Blumenau (FURB). É professor Adjunto I da Universidade Federal do Amazonas (UFAM). E-mail: jonaspetry@brturbo.com.br (Brasil)

\section{RESUMO}

As políticas públicas desenvolvidas pelo Estado têm importância fundamental na sociedade, tendo em vista que ela proporciona de forma igualitária melhorias na vida dos cidadãos e influencia direta ou indiretamente no modo de viver de cada indivíduo. Desse modo, foi promulgada em 2006 a Lei n. 11.326, que reconhece oficialmente a agricultura familiar como profissão. Sendo assim, foram criadas políticas públicas específicas de estímulo aos agricultores familiares. Nesse contexto, considerando a relevância do tema em questão, foi definido como objetivo do trabalho analisar a importância das Políticas Públicas voltadas para a agricultura familiar como meio de desenvolvimento socioeconômico na Associação Novo Horizonte, localizada no município de Tabatinga (AM). Esta pesquisa foi desenvolvida de forma exploratória e descritiva, com a aplicação de survey e técnicas de observação. Os resultados indicam que a maioria dos associados não possui conhecimentos sobre a oferta de Políticas Públicas de incentivo à Agricultura Familiar, assim como constatou as principais dificuldades encontradas para a realização das atividades agrícolas como, por exemplo, a falta de apoio dos órgãos competentes. Nesse sentido, apontou a necessidade de investimento na infraestrutura, o que representa a melhoria na pavimentação das estradas que dão acesso à zona rural.

PALAVRAS-CHAVE: Políticas públicas. Associativismo. Agricultura Familiar. 


\title{
Public family agriculture policies in provincial areas of the state of
}

\author{
Amazonas, Brazil
}

\begin{abstract}
Public policies established by the State have a fundamental importance in society, since they aim to provide citizens with equal access to improvements in living standards and have direct and indirect impacts on the way everybody lives. For example, a law which was approved in 2006 (Law number 11.326) officially recognized family agriculture as a profession, enacting specific public policies to provide incentives for family agriculture. It is against this background, and considering the relevance of the subject, that this study was conducted with the objective of analyzing the importance of Public Policies related to family agriculture as a means of socioeconomic development, focusing on the "Associação Novo Horizonte", located in the municipal district of Tabatinga, AM, Brazil. This was an exploratory and descriptive research project employing survey methods and observational techniques. The results showed that the majority of association members did not know about the existence of the Public Policies to provide incentives for Family Agriculture. The study also identified the principal difficulties faced by those engaged in agricultural activities, such as, for example, a lack of support from the competent organs, and revealed a need for investment in infrastructure, specifically in improvements to the surfaces of the roads that provide access to rural areas.
\end{abstract}

KEYWORDS: Public policies. Association activism. Family agriculture.

\section{Como referenciar em APA:}

Rodrigues, B. S., Simão, F. C. \& Petry, J. F. (2018). Políticas públicas para agricultura familiar no interior do estado do Amazonas. R.G.Secr.,GESEC, 9(1). doi: http://dx.doi.org/10.7769/gesec.v9i1.723

\section{Como referenciar em ABNT:}

RODRIGUES, B. S.; SIMÃO, F. C.; PETRY, J. F. Políticas públicas para agricultura familiar no interior do estado do Amazonas. R.G.Secr.,GESEC, v. 9, n. 1, 2018. doi: http://dx.doi.org/10.7769/gesec.v9i1.723

\section{THOMSON REUTERS}
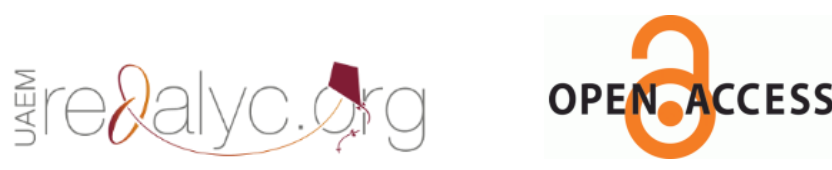

R.G. Secr., GESEC, São Paulo, v. 9, n. 1, p 208-235, jan./abr. 2018. 
Rodrigues, B. S., Simão, F. C. \& Petry, J. F. (2018).

\section{Introdução}

As políticas públicas desenvolvidas pelo Estado têm grande peso na vida das pessoas, pois as decisões dos políticos podem promover desenvolvimento ou atraso, riqueza ou miséria e, principalmente, podem acelerar ou não o crescimento das empresas privadas (Araújo, Canteri, Bittencout, \& Rodrigues, 2017). Entende-se que as políticas norteiam as condutas dos gestores públicos para a relação do Estado com a Sociedade, sendo formuladas por meio de leis, normas, decretos ou até mesmo programas para a sua aplicação efetiva, proporcionando melhorias na qualidade de vida de todos os seus cidadãos (Cornwall \& Brock, 2005; Cabral, Favareto, Mukwereza, \& Amanor, 2016). Com isso, as políticas públicas são importantíssimas na sociedade, tendo em vista que elas proporcionam de forma igualitária melhorias na vida dos cidadãos e influenciam direta ou indiretamente no modo de viver de cada indivíduo. Mas a sua principal finalidade é a de promover o bem comum, buscando de forma democrática atender as necessidades e aspirações da sociedade (Chamhuri, Hamdan, Ahmah, \& Ismail, 2015).

Nesse sentido, a literatura sobre a agricultura familiar aponta que, desde meados da década de 1990, vem ocorrendo um processo de reconhecimento e de criação de instituições de apoio a esse modelo de agricultura (Van Vliet et al., 2015; Stavropoulou, Holmes \& Jones, 2017; Nehring, Miranda \& Howe, 2017). Foram criadas políticas públicas específicas de estímulo aos agricultores familiares, como o Programa Nacional de Fortalecimento da Agricultura Familiar, em 1995, secretarias de governo orientadas exclusivamente para trabalhar com a categoria (como a Secretaria da Agricultura Familiar, criada em 2003 no âmbito do Ministério do Desenvolvimento Agrário, criado em 1998).

Promulgou-se em 2006 a Lei da Agricultura Familiar, reconhecendo oficialmente a agricultura familiar como profissão no mundo do trabalho e foram criadas organizações de representação sindical com vistas a disputar e consolidar a identidade política de agricultor familiar. Além do mais, a elaboração de um caderno especial sobre a Agricultura Familiar com os dados do Censo Agropecuário de 2006 (IBGE, 2009) contribuiu para evidenciar a importância social e econômica dessa categoria de agricultores no país.

Com base nisso, buscando criar políticas para desenvolver economicamente uma área com atividade intensa no país, a agricultura familiar vem se destacando no cenário nacional devido a sua importância na garantia da segurança alimentar dos brasileiros (Oliveira, Collado \& Leite, 2013; Van Vliet et al., 2015). Diante dessa realidade, políticas públicas de fomento 
têm sido direcionadas a essa parcela da sociedade com o objetivo de elevar o potencial de produção desses agricultores e possibilitar a permanência de parte das famílias na área rural, bem como a continuidade de sua produção e mão de obra, que abastece os mercados regionais e locais.

O município de Tabatinga, interior do estado do Amazonas, localizado na mesorregião do sudoeste amazonense e microrregião do Alto Solimões é uma área bastante rica em produtos naturais, local ideal para o desenvolvimento dessa atividade e incentivo por parte do governo municipal, apoiando a prática de continuidade da produção dos alimentos que abastecem Tabatinga e regiões próximas. É também o caso do município localizado no país vizinho, Letícia/Colômbia, abrindo um nicho importante no mercado internacional.

Diante do exposto, o objetivo deste estudo é analisar o efeito das Políticas Públicas na Agricultura Familiar. Para isso, a investigação foca seus esforços na Associação dos Agricultores Rurais, uma comunidade localizada em Novo Horizonte, no município de Tabatinga, no estado do Amazonas.

Além da introdução, este manuscrito está dividido em cinco seções. A seção dois foi dedicada à fundamentação teórica. $\mathrm{Na}$ seção três são apresentados os procedimentos metodológicos. A seção quatro apresenta os resultados. Na seção cinco estão as considerações finais, seguidas das referências.

\section{Referencial Teórico}

A função que o Estado desempenha na sociedade sofreu inúmeras transformações com o passar do tempo. No século XVIII e XIX, seu principal objetivo era a segurança pública e a defesa externa em caso de ataque inimigo (Mohan, 2017). Entretanto, com o aprofundamento e a expansão da democracia, as responsabilidades do Estado diversificaram-se. Atualmente, é comum afirmar-se que a função do Estado é a de promover o bem-estar da sociedade (Aked, Michaelson \& Steuer, 2010). Para isso, o Estado necessita desenvolver uma série de ações e atuar diretamente em diferentes áreas, tais como saúde, educação, segurança, meio ambiente.

Para que o governo possa atingir resultados em suas diversas áreas e promover o bemestar da sociedade, utiliza-se das Políticas Públicas, que podem ser definidas como um campo dentro do estudo da política que analisa o governo à luz de grandes questões públicas, buscando uma solução ou a melhor solução para os problemas sociais (Mead, 1995). 
Rodrigues, B. S., Simão, F. C. \& Petry, J. F. (2018).

Lynn (1980) contribui para esta definição afirmando que políticas públicas são um conjunto de ações do governo que vão produzir efeitos específicos em uma sociedade. Já Peters (1986) afirma que é a soma das atividades dos governos, que agem diretamente ou por meio de delegação, que influencia a vida dos cidadãos, enquanto Dye (1984) sintetiza a definição de política pública como o que o governo escolhe fazer ou não fazer.

Todas essas definições sobre políticas públicas dão ênfase à realização de uma atividade pública feita por meio de agentes públicos em busca das melhores decisões do governo para a sociedade (Petrini, Rocha, Brown, \& Bispo, 2016). Dito de outra maneira, essas políticas formam uma totalidade de ações, metas e planos que o governo traça para alcançar o bem-estar da sociedade e o interesse público. É certo que as ações que os agentes públicos selecionam são aquelas que eles entendem serem as demandas ou expectativas da sociedade, ou seja, o bem-estar da sociedade é sempre definido pelo governo e não pela sociedade.

\subsection{Atores das políticas públicas}

Faz-se necessário compreender também os atores que integram o sistema político, pois eles são determinantes na atuação do governo, sejam eles atores políticos, sejam sociais, que, independentemente, contribuem de forma única para o progresso nas mais diversas áreas do Estado. Portanto, são denominados atores os grupos que integram o Sistema Político, apresentando reivindicações ou executando ações que serão transformadas em políticas públicas. Teixeira (2002) agrega valor ao conceito de políticas públicas. O autor afirma que são diretrizes norteadoras que regem as relações entre poder público e sociedade, por meio de mediações entre atores da Sociedade e do Estado.

São chamados de atores políticos ou atores sociais os membros de grupos que integram o sistema político. Em todo o processo de elaboração até a análise das políticas públicas são encontrados dois tipos de atores, os estatais ou públicos, estes ligados diretamente ao Governo ou Estado, e os privados, grupos provenientes da sociedade civil, como a base trabalhadora, empresários, mídia, entre outros setores que compõe a sociedade (Teixeira, 2002).

Existe uma importante diferença no modo de agir de cada um desses segmentos. Os políticos são eleitos com base em suas propostas de políticas apresentadas para a população durante o período eleitoral e buscam tentar realizá-las. Já os atores privados são aqueles que 
não possuem vínculo direto com a estrutura administrativa do Estado. Fazem parte desse grupo:
a) a imprensa;
b) os centros de pesquisa;
c) os grupos de pressão, os grupos de interesse e os lobbies;
d) as associações da Sociedade Civil Organizada (SCO);
e) as entidades de representação empresarial;
f) os sindicatos patronais;
g) os sindicatos de trabalhadores;
h) outras entidades representativas da SCO.

É importante enfatizar que esses atores privados têm papel importante na sociedade. Além de gerar emprego e renda para a população, eles ajudam a alavancar a economia do nosso país, pois atuam de forma isolada e, às vezes, em parceria com instituições que possuem os mesmos interesses para que assim trabalhem em prol de objetivos organizacionais que devem ser atingidos pelos colaboradores.

\subsection{A importância das políticas públicas para o incentivo à agricultura familiar}

Ao abordar o tema agricultura familiar, é importante conhecer a sua conceituação. No Brasil, essa conceituação foi formulada com a Lei n. 11.326, de 24 de julho de 2006, que estabelece as diretrizes para a formulação da Política Nacional da Agricultura Familiar e Empreendimentos Familiares Rurais, com o seguinte enunciado:

Artigo 3- - Para fins desta lei, considera-se agricultor familiar e empreendedor familiar rural aquele que pratica atividades no meio rural, atendendo, simultaneamente, aos seguintes requisitos: I) Não detenha a qualquer título, área maior que 4 módulos fiscais; II) Utilize predominantemente mão de obra da própria família nas atividades econômicas do seu estabelecimento ou empreendimento; III) Tenha percentual mínimo de renda familiar originada de atividades econômicas do seu estabelecimento ou empreendimento, na forma definida pelo Poder executivo; (Lei 12.512, de 2011); IV) Dirija seu estabelecimento ou empreendimento com sua família.

A Lei conceitua o agricultor familiar definindo seus requisitos. Tal conceituação torna aquele que pratica a agricultura familiar mais visível, mais facilmente identificável. Há também aqueles autores que conceituam a agricultura familiar em seus estudos. Complementando essa definição, Noda (2006) diz que o trabalho dentro da propriedade existe e torna-se necessário para a sobrevivência da família, pois ela realiza a agricultura principalmente para seu sustento. 
Rodrigues, B. S., Simão, F. C. \& Petry, J. F. (2018).

Ao ponderar as definições da lei e de autores como Noda (2006) sobre o que é agricultura familiar, nota-se que o objetivo maior dessa atividade é a autossobrevivência dos agricultores; as suas propriedades são pequenas e o trabalho é realizado pela própria família. Esses são alguns dos fatores que caracterizam a agricultura familiar de um modo geral.

As políticas públicas afetam todos os indivíduos, independentemente de sexo, cor, religião, raça ou nível de renda e envolve todos os atores que, direta ou indiretamente, lidam com essa questão no seu dia a dia. Com base na cartilha Políticas Públicas para Agricultura Familiar, elaborada pelo Ministério do Desenvolvimento Agrário, foram relacionados diversos programas, tais como:

a) Programa Nacional de Fortalecimento da Agricultura Familiar (Pronaf), muito importante para a população rural, pois disponibiliza recursos financeiros para que o agricultor familiar possa fazer algum tipo de financiamento para dar início ao seu negócio. O programa conta com várias linhas de crédito para os mais diferentes tipos de investimento, sejam eles projetos individuais ou coletivos e que possam gerar renda aos agricultores de base familiar;

b) A Assistência Técnica e Extensão Rural (Ater) é um programa que tem como principal objetivo levar assistência técnica aos agricultores, para que possam adquirir conhecimentos técnicos e melhorar a sua produção, tendo seus produtos com melhor qualidade e com maiores oportunidades de serem inseridos no mercado. Mas, para isso, o programa trabalha com instituições que auxiliam o agricultor a levar seu produto ao consumidor final, tendo assim maiores chances de vendê-lo e, consequentemente, aumentar a renda das famílias;

c) O Programa Nacional de Alimentação Escolar (Pnae) foi instituído pela Lei $\mathrm{n}$. 11.947/2009, e é um programa que prevê a compra de, no mínimo, 30\% dos alimentos provenientes da agricultura familiar para serem servidos nas escolas da rede pública de ensino. Esse programa dá oportunidade ao agricultor familiar, pois lhe é garantido que $30 \%$ dos alimentos da merenda escolar devem ser adquiridos por meio da agricultura familiar. Tal aquisição se dá por meio de chamadas públicas, assegurando uma renda fixa mensalmente às famílias participantes desta referida modalidade, desfrutando de uma situação mais estável e não passando por dificuldades em suas vendas, tendo em vista que a compra é garantida pelo governo. 


\subsection{A agricultura familiar no estado do Amazonas e no município de Tabatinga (AM)}

Noda (2006) observa o seguinte sobre a agricultura familiar no Amazonas:

Ela é praticada em ambientes pouco modificados, que não sofreram, ainda, os impactos negativos do avanço da agropecuária estritamente voltada aos mercados ou das ações de projetos de desenvolvimento de grande porte voltados à exploração de recursos naturais. Sua produção é diversificada e, além de permitir uma oferta constante, ampla e variada de alimentos para o autoconsumo, proporciona maior estabilidade ao sistema produtivo, pois o suprimento das necessidades básicas em alimentos da família independe da comercialização, as crises do mercado podem afetar o núcleo produtivo, mas não inviabilizam sua sobrevivência.

Nessa citação pode destacar-se que, além de sustento para a família, a agricultura familiar no estado do Amazonas apresenta-se bastante diversificada. Ela não é uma monocultura; o produtor familiar amazônico, de modo geral, preocupa-se em cultivar diversos produtos.

O município de Tabatinga possui uma área territorial de $3.266,062 \mathrm{~km}^{2}$ e uma população de 61.028, conforme dados do Instituto Brasileiro de Geografia e Estatística (IBGE) em 2015. Possui 64 comunidades, distribuídas ao longo da margem esquerda do rio Solimões, igarapé do Tacana, igarapé de Belém do Solimões, Crajari e área do projeto de Assentamento Urumutum. A Figura 1 representa a vista aérea do município de Tabatinga.

Figura1 - Vista aérea do município de Tabatinga (AM).

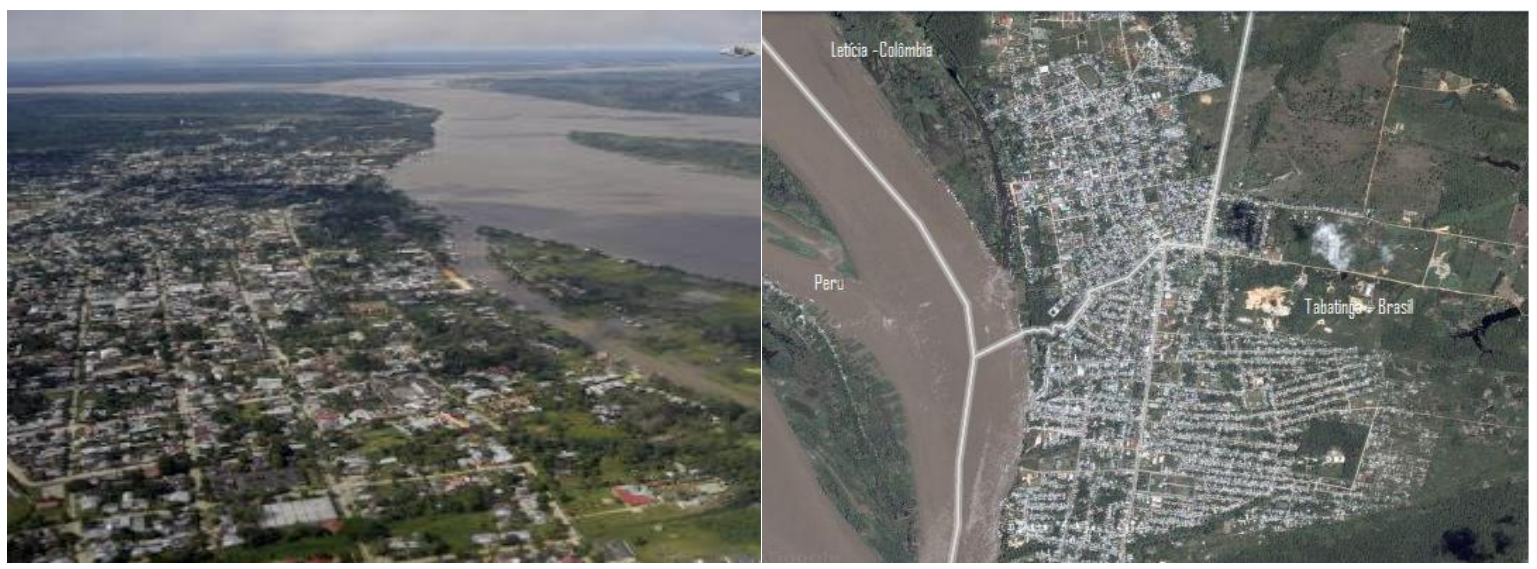

Fonte: Google Maps (2017).

No Plano Operativo (PO) 2016, que é um plano elaborado pelo Instituto de Desenvolvimento Agropecuário e Florestal Sustentável do Estado do Amazonas (Idam), que serve como uma ferramenta de auxílio para executar as atividades de campo do órgão, verificando e registrando todas as informações das atividades rurais nas comunidades do município, unidade de Tabatinga (AM), está atendendo 18 comunidades, sendo sete 
Rodrigues, B. S., Simão, F. C. \& Petry, J. F. (2018).

localizadas em área de várzea à margem esquerda do rio Solimões, 11 localizadas no Projeto de Assentamento Urumutum, no ecossistema de terra firme. As comunidades assistidas estão descritas no quadro abaixo.

Quadro 1 - Comunidades assistidas pelo Idam em 2016 no município de Tabatinga (AM).

\begin{tabular}{|c|c|c|}
\hline $\mathbf{N}$ & Comunidade Assistida & Área de Localização \\
\hline 1 & Novo Horizonte & \multirow{11}{*}{ Projeto de Assentamento Urumutum } \\
\hline 2 & Novo Progresso & \\
\hline 3 & Novo Paraíso & \\
\hline 4 & São João & \\
\hline 5 & Urumutum Tacana & \\
\hline 6 & Deus é Bom & \\
\hline 7 & Bom Jesus & \\
\hline 8 & Floresta Tropical & \\
\hline 9 & Geodésica I & \\
\hline 10 & Belém do Solimões (indígena) & \\
\hline 11 & Vila Nova Esperança (indígena) & \\
\hline 12 & Limeira & \multirow{7}{*}{ Área de várzea } \\
\hline 13 & Praia de Fátima & \\
\hline 14 & Vila Nova & \\
\hline 15 & Terezina I & \\
\hline 16 & Araçari & \\
\hline 17 & Terezina IV & \\
\hline 18 & Bom Futuro & \\
\hline
\end{tabular}

De acordo com o PO, os agricultores familiares da área de várzea (planície de inundação), com o passar dos anos, vêm tendo dificuldades de cultivar devido às constantes subidas das águas do rio Solimões, o que ocasiona perda de toda a produção, porém continuam cultivando alguns produtos, como mandioca, banana, milho, feijão, hortaliças. Por essa razão, muitos dos agricultores ribeirinhos migraram para a pesca artesanal, pois o produto dessa atividade tem grande espaço no mercado regional e no município com que Tabatinga faz fronteira com o país vizinho, Letícia/Colômbia, conhecida como cidade-gêmea, pois seu acesso se dá diretamente por terra.

No extrativismo local, de acordo com o PO do Idam, as comunidades indígenas destacam-se na coleta do açaí e vêm aumentando o cultivo de produtos como as hortaliças em campo aberto e protegido. Com o apoio da prefeitura municipal, essa ação vem aumentado cada vez mais.

Para uma assistência mais atuante aos agricultores familiares, a prefeitura municipal vem se estruturando com técnicos da Secretaria de Produção Rural Municipal para atender as comunidades que não estão contempladas no PO de 2016, ajudando o governo do Estado a 
aumentar a assistência técnica e extensão rural e florestal a todas as comunidades do município. O PO tem como parceiros no ano de 2017, para o cumprimento das metas programadas, instituições como: Prefeitura Municipal, Instituto Federal do Amazonas (Ifam) - campus Tabatinga, Sindicato dos Trabalhadores, Colônia e Sindicato de Pescadores, Diocese do Alto Solimões, Banco do Brasil, Agência de Fomento do Estado do Amazonas (Afeam), Banco da Amazônia S/A (Basa) e Serviço Brasileiro de Apoio às Micro e Pequenas Empresas (Sebrae). Tais parcerias ocorrem de forma direta, com visitas frequentes das instituições como Idam e Ifam nas comunidades assistidas para que assim possam dar assistência técnica aos agricultores familiares, verificando e dando orientação sobre a produção de cada família assistida.

\section{Metodologia}

O objeto de estudo da pesquisa é a associação dos Agricultores Rurais da Comunidade de Novo Horizonte (AAR), inscrita no CNPJ sob o n. 11.007.495/0001-05, atuante no setor de agropecuária, que se encontra localizada na estrada Geodésica II, Projeto de Assentamento Urumutum, Zona Rural do Município de Tabatinga/Amazonas.

Conforme entrevista realizada com o presidente da AAR, identificou-se que as atividades da comunidade se iniciaram em 2004, porém foi só em 2007 que foi fundada legalmente como AAR. Conta atualmente com um total de 32 associados efetivos, que realizam o pagamento de uma taxa mensal de $\mathrm{R} \$ 10,00$ na conta bancária da associação. Vale ressaltar que no ano de fundação o valor era de $\mathrm{R} \$ 3,00$ mensais, porém, com o passar do tempo, o valor foi aumentado para $\mathrm{R} \$ 5,00$ mensais, e hoje, por meio de acordo em assembleia, o valor foi estabelecido em $\mathrm{R} \$ 10,00$.

O presidente da associação informou ainda que quando uma pessoa quer associar-se, ela tem de comprovar que é agricultora e que mora na comunidade. O novo associado é apresentado aos demais membros na assembleia subsequente e a sua situação é formalizada por registro em ata. Por outro lado, quando uma pessoa quer pedir desligamento da associação, ela tem de fazer uma declaração pedindo sua desfiliação. Só assim ela estará totalmente desligada da associação.

Marconi e Lakatos (2009) afirmam que "amostra é uma parcela conveniente selecionada do universo (população); é um subconjunto do universo". Corroborando essa ideia, Acevedo e Nohara (2007) descrevem amostra como uma parte da população ou 
Rodrigues, B. S., Simão, F. C. \& Petry, J. F. (2018).

universo. Desse modo, a amostra usualmente envolve o estudo de uma parcela dos itens de uma população.

Diante do exposto, a amostra apresentada contém os agricultores familiares que fazem parte da Associação Novo Horizonte, localizada na comunidade do Umariaçu. A referida pesquisa foi realizada com 17 agricultores familiares encontrados no momento da aplicação da pesquisa, que se deu no período de 26 a 30 de junho de 2017.

Quanto ao tipo de abordagem, a pesquisa pode ser classificada como qualitativa. Tal pesquisa qualitativa tende a salientar os aspectos dinâmicos, holísticos e individuais da experiência humana para apreender a totalidade no contexto daqueles que estão vivenciando o fenômeno (Polit, Becker \& Hungler, 2004).

Utilizou-se também como abordagem de pesquisa para o referido estudo a estatística descritiva, que "compreende o manejo dos dados para resumi-los ou descrevê-los, sem ir além, isto é, sem procurar inferir qualquer coisa que ultrapasse os próprios dados" (Freund \& Simon, 2000). Diferentemente da análise confirmatória de dados, que busca poder concluir a partir de amostras para uma população inteira, a estatística descritiva, ou análise exploratória, foca somente em resumir, descrever ou apresentar dados (Collis \& Hussey, 2005). Para Freund e Simon (2000), a estatística descritiva possui limitações ligadas ao fato de os dados serem, na maioria das vezes, obtidos de amostras, o que incita generalizações por parte do analista.

Neste estudo, abordam-se métodos mais tradicionais da estatística descritiva, não sendo objetivo apresentar técnicas relativamente novas de análise exploratória de dados. Considerou-se estatística descritiva todo agrupamento de dados em tabelas ou gráficos encontrados nos dados coletados, tendo sido objeto da análise para responder aos objetivos da pesquisa.

Este trabalho foi desenvolvido de forma exploratória e descritiva, abrangendo os aspectos como: perfil dos associados, políticas públicas de fomento da referida atividade e o aspecto socioeconômico, foco do estudo. A pesquisa exploratória tem como objetivo proporcionar maior familiaridade com o problema, com vistas a torná-lo mais explícito ou a construir hipóteses. A maioria dessas pesquisas envolve:

a) levantamento bibliográfico;

b) entrevistas com pessoas que tiveram experiências práticas com o problema pesquisado; e

c) análise de exemplos que estimulem a compreensão (Gil, 2007). 
Já a pesquisa descritiva exige do investigador uma série de informações sobre o que deseja pesquisar. Para Triviños (1987), os estudos descritivos podem ser criticados porque pode existir uma descrição exata dos fenômenos e dos fatos. Estes fogem da possibilidade de verificação por meio da observação. Ainda para o autor, às vezes não existe por parte do investigador um exame crítico das informações, e os resultados podem ser equivocados; e as técnicas de coleta de dados, como questionários, escalas e entrevistas, podem ser subjetivas, apenas quantificáveis, gerando imprecisão.

Os procedimentos utilizados para alcançar os objetivos estabelecidos da pesquisa foram a pesquisa bibliográfica, a observação, a entrevista semiestruturada e a aplicação de questionário. Cada um contém sua similaridade e especificidade, contribuindo para o alcance dos objetivos definidos na pesquisa da melhor forma possível.

\section{Análise e Discussão dos Resultados}

\subsection{Perfil do associado}

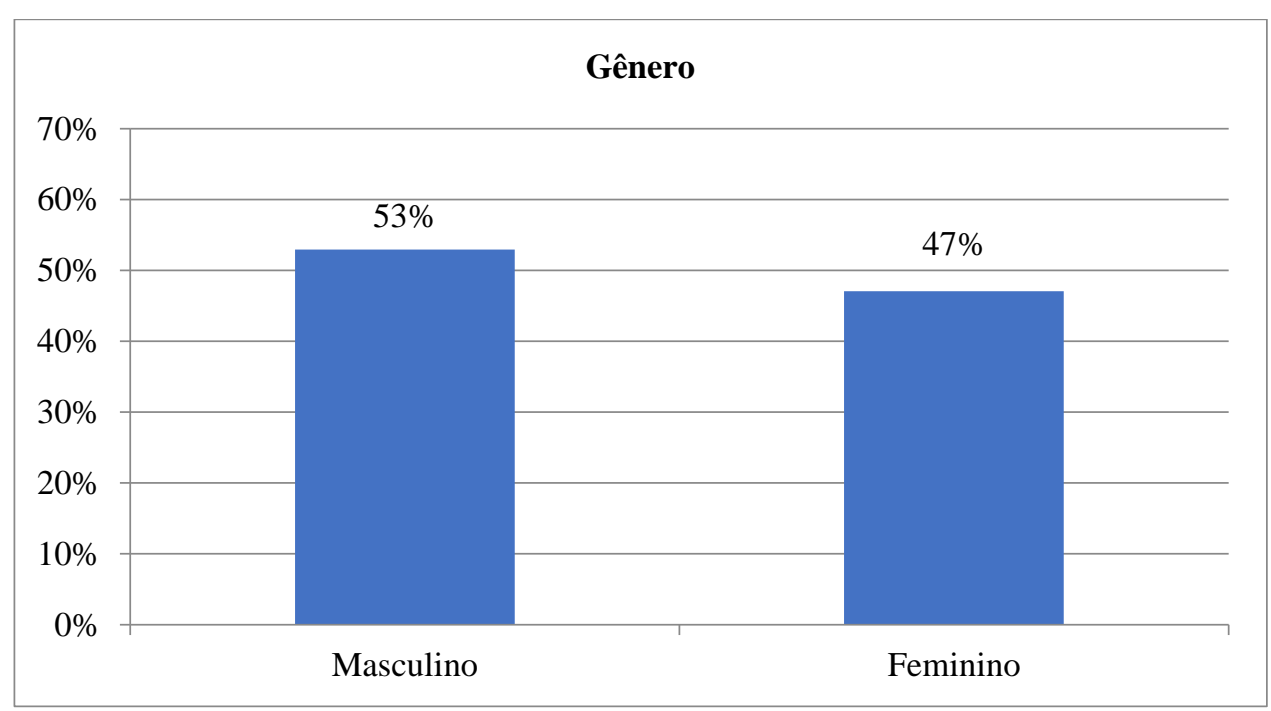

Gráfico 1 - Gênero dos agricultores da AAR.

Os resultados obtidos por meio da pesquisa de campo referente ao gênero dos agricultores mostrou que homens e mulheres estão bastante envolvidos com a referida atividade. Todavia, na análise do Gráfico 1, observa-se que 53\% são representados pelo sexo masculino, enquanto 47\% são representados pelo sexo feminino.

É importante ressaltar que apesar de os homens terem um percentual acima do das mulheres quanto a sua participação na atividade, ambos trabalham juntos, pois essa é uma 
Rodrigues, B. S., Simão, F. C. \& Petry, J. F. (2018).

atividade familiar em que todos os envolvidos participam, desde o pai, mãe até os filhos, unindo forças para garantir o seu alimento de cada dia. Nota-se ainda que o Gráfico 1 apresenta resultado equilibrado quanto ao gênero dos associados da AAR, pois tal atividade é realizada tanto por mulheres quanto por homens, o que torna a atividade, conforme demonstra o gráfico, equilibrada.

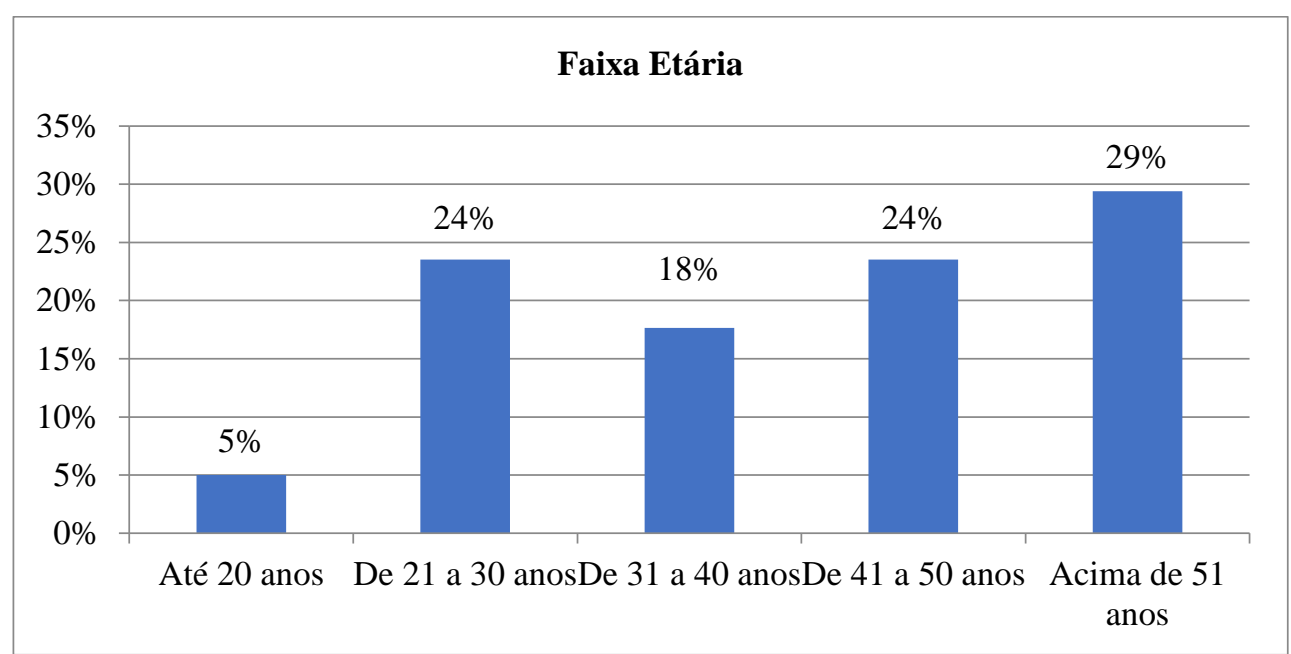

Gráfico 2 - Faixa etária dos agricultores da AAR.

O Gráfico 2 apresenta a faixa etária dos agricultores pesquisados, que varia de até 20 anos a acima de 51 anos, havendo uma média de idade equilibrada na comunidade. É importante observar que $29 \%$ dos agricultores têm idade acima de 51 anos, sendo a maioria e os fundadores da comunidade em que residem. Em seguida, $24 \%$ deles encontram-se na faixa etária de 21 a 30 anos e de 41 a 50 anos, ambos seguidos de um percentual de $18 \%$ dos agricultores com a idade de 31 a 40 anos. Por conseguinte, 5\% desses encontram-se com idade de até 20 anos, iniciando bem cedo suas atividades rurais.

Conforme demonstra o Gráfico 2, há um percentual significativo da faixa etária acima de 51 anos, fato este que se dá devido a uma questão cultural, pois esses agricultores iniciaram ainda jovens suas atividades rurais, não dispondo de tempo e tendo poucas oportunidades para buscar uma formação educacional de qualidade, já que quando eram mais novos não havia oportunidades de formação profissional como há hoje em dia, como a presença de instituições de ensino técnico e superior no município que dão suporte para que o indivíduo possa buscar melhor qualificação profissional.

Considera-se também um percentual igual referente à faixa etária dos 21-30 e 41-50 anos, consagrando-se neste momento a inclusão de jovens agricultores na associação. 


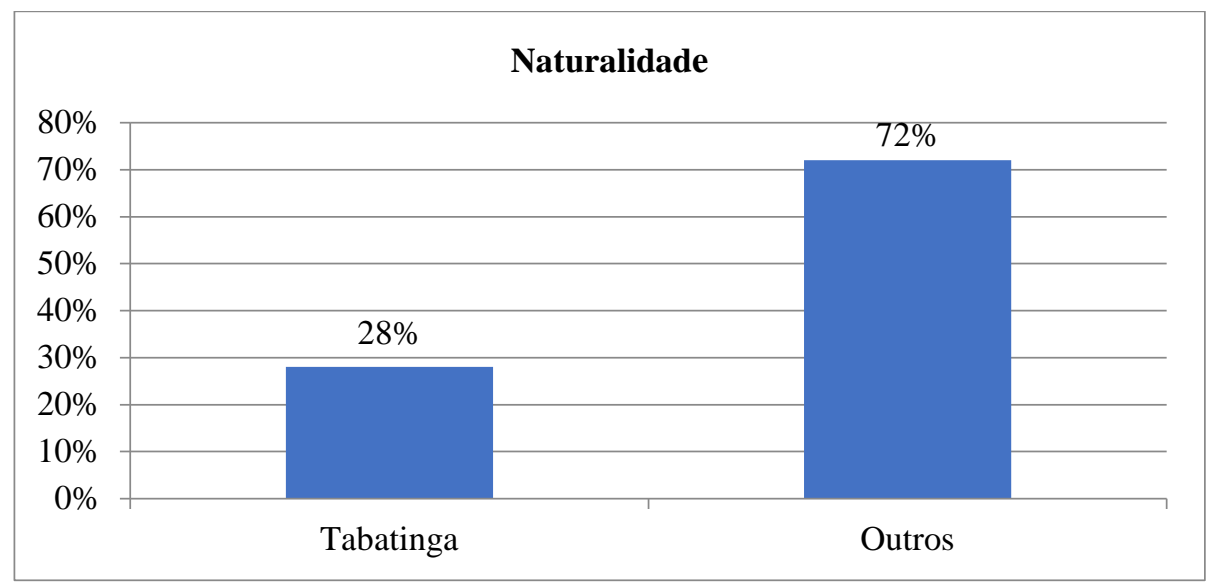

Gráfico 3 - Naturalidade dos agricultores da AAR.

Conforme os dados demonstrados no Gráfico 3, apenas $28 \%$ dos entrevistados são naturais de Tabatinga, município onde nasceram e cresceram com suas famílias ao longo dos anos. E com um elevado percentual de $72 \%$ aparecem os associados que são naturais de outros municípios.

Quanto aos agricultores naturalizados de outros municípios, temos uma grande taxa pertencente ao município de Atalaia do Norte, com 18\%, seguido de Letícia, com 18\%. Benjamin Constant e Santo Antônio do Iça aparecem com uma taxa de $12 \%$ cada um e, por fim, Codajás e Amaturá, ambos com $6 \%$ cada um, conforme quadro abaixo.

Quadro 2 - Naturalidade dos agricultores da AAR.

\begin{tabular}{|l|c|c|}
\hline Naturalidade & Fi & $\mathbf{f}(\boldsymbol{\%})$ \\
\hline Atalaia do Norte & 3 & 18 \\
\hline Letícia & 3 & 18 \\
\hline Benjamin Constant & 2 & 12 \\
\hline Santo Antônio do Iça & 2 & 12 \\
\hline Codajás & 1 & 6 \\
\hline Amaturá & 1 & 6 \\
\hline Total & 12 & $72 \%$ \\
\hline
\end{tabular}

Esse alto índice de pessoas naturalizadas de outros municípios que migraram para Tabatinga pode ser justificado pelo fato de o município apresentar alguns fatores fundamentais para o desenvolvimento da atividade rural. Alguns desses fatores podem ser compreendidos como o potencial produtivo que o município apresenta para a atuação desses agricultores na região, assim como as parcerias que a AAR possui com instituições como o Idam, o Ifam e Sebrae. 
Rodrigues, B. S., Simão, F. C. \& Petry, J. F. (2018).

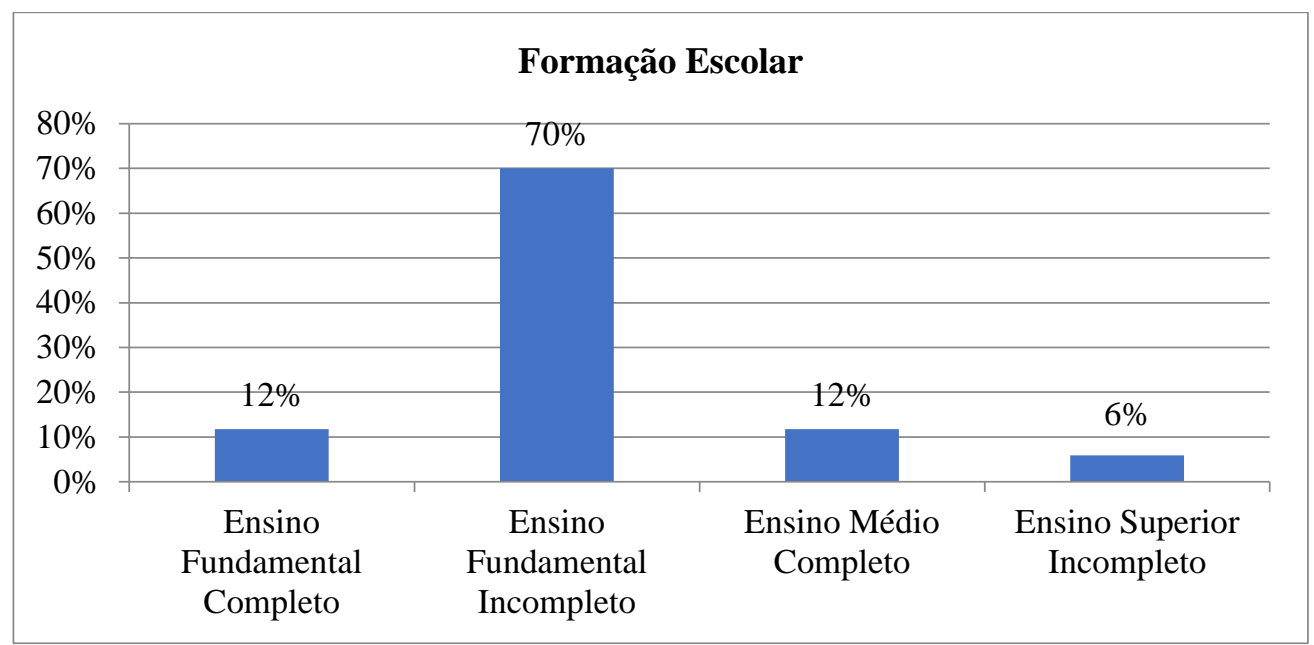

Gráfico 4 - Formação escolar dos agricultores da AAR.

Em relação à formação escolar dos associados, conforme Gráfico 4, pode-se observar que $70 \%$ possuem ensino fundamental incompleto, $12 \%$ possuem ensino fundamental completo e outros $12 \%$ possuem o ensino médio completo. Apenas $6 \%$ possuem o ensino superior incompleto, ou seja, ainda estão em processo de conclusão de curso.

Essa elevada taxa referente ao ensino fundamental incompleto deve-se ao fato de os associados começarem a trabalhar ainda jovens na agricultura, não dispondo de tempo para os estudos e, algumas vezes, oportunidades para que pudessem receber educação básica de qualidade. Além disso, a dedicação à família também é um fator determinante para a sua formação como pessoa, buscando repassar os ensinamentos que adquiriram com o tempo para seus filhos.

Observou-se também que há uma pequena parcela dos associados que procura investir em uma formação profissional de qualidade por meio de cursos técnicos, como o Técnico em Agropecuária e o Técnico em Piscicultura. Outros, ainda, buscam o ensino superior, tendo em vista que nosso município e arredores dispõe de instituições de ensino técnico, como o Centro Tecnológico Educacional do Amazonas, o Instituto Federal do Amazonas, assim como os de ensino superior, como a Universidade do Estado do Amazonas, a Universidade Federal do Estado do Amazonas e diversas outras instituições de natureza privada que hoje ajudam um indivíduo a qualificar-se para o mercado de trabalho.

Para Lima e Wilkinson (2002), novos conhecimentos são uma precondição para a permanência da agricultura familiar mesmo em mercados tradicionais e muito mais no caso da busca de novas formas de inserção econômica.

Conforme dados coletados na entrevista com o presidente da AAR, identificou-se que o grande percentual dos associados que possuem o ensino fundamental incompleto procura 
fazer alguns cursos, treinamentos e participar de palestras ministradas por instituições como o Sebrae, o Idam e o Ifam. Assim, buscam aquisição de conhecimento e adoção de novas técnicas de cultivo, e tentam capacitar-se cada vez mais.

Pode-se também fazer uma relação com o Gráfico 2, que diz respeito à faixa etária dos associados: a maioria apresenta faixa etária mais elevada, fato este que está de acordo com os dados obtidos no Gráfico 4, pois identificou-se que os associados não possuíam as oportunidades que há hoje em dia para se qualificar e obter nível de escolaridade maior.

\subsection{Oferta de políticas públicas}

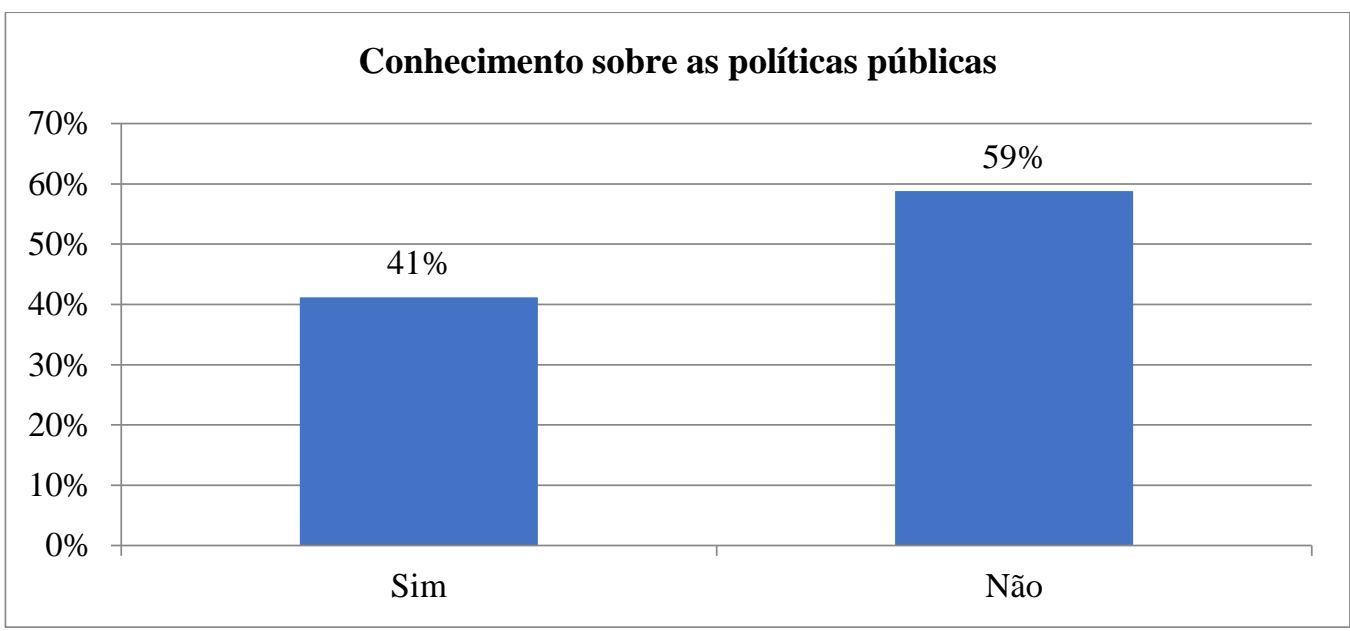

Gráfico 5 - Conhecimento das políticas públicas para a Agricultura Familiar.

O Gráfico 5 diz respeito ao conhecimento que os agricultores têm acerca das políticas públicas voltadas para o desenvolvimento da atividade que eles exercem. Com isso, a pesquisa identificou que 59\% dos agricultores não têm conhecimento das políticas públicas voltadas para o desenvolvimento da agricultura familiar, pois quando questionados sobre os programas, não souberam responder com clareza do que se tratava.

É importante destacar a falta da aplicação de um dos princípios do associativismo, que estabelece que as associações devam promover a educação e a formação de seus membros de modo que estes possam contribuir eficazmente para o desenvolvimento da associação, e neste caso inclui a necessidade de conhecer quais as políticas públicas que podem alavancar as atividades da AAR.

Por outro lado, há uma parcela significativa de $41 \%$ que têm conhecimento sobre algumas políticas públicas, como Pronaf e Ater, que, por vezes, chegaram a realizar empréstimos para investir em seu negócio familiar. E esse número tende a aumentar devido ao 
Rodrigues, B. S., Simão, F. C. \& Petry, J. F. (2018).

alto grau de interesse que os associados vêm tendo em participar mais ativamente da associação.

Portanto, para que a AAR possa usufruir dos benefícios concedidos pelo Governo Federal por meio dos programas apresentados, é necessário que haja a obtenção da DAP Jurídica da mesa. Mas foi identificado na entrevista realizada com o presidente que a Associação ainda não possui tal registro, o qual possibilita a identificação dos associados como agricultor familiar, fato este que explica a falta de adesão aos programas do Governo Federal.

Com isso, observa-se quanto a associação está perdendo pela não obtenção da DAP Jurídica para participar de programas como o PAA, que tem sua importância fundamental na disponibilização de produtos naturais para órgãos municipais, podendo, assim, usufruir de uma condição financeira mais estável, buscando elevar a sua renda e, consequentemente, melhoria na qualidade de vida das famílias.

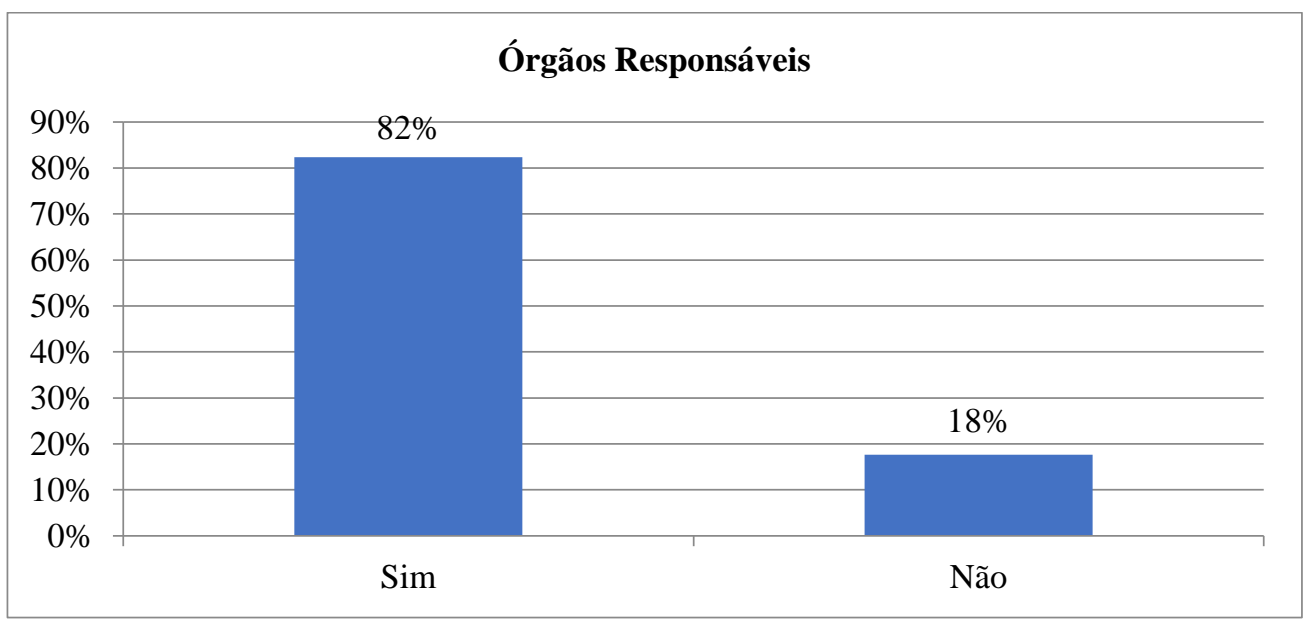

Gráfico 6 - Atuação dos órgãos responsáveis pelas políticas públicas

O Gráfico 6 mostra que 82\% dos agricultores familiares recebem visitas de instituições como o Idam, que, em parceria com o Ifam-campus Tabatinga, contribui de forma significativa, dando orientações de plantio, cultivo, criação e assistência técnica no que eles necessitam para aperfeiçoar suas habilidades. Porém, alguns deles informaram que só recebem visitas do Idam quando este tem de apresentar um relatório, chegando às residências rurais e fazendo apenas perguntas por meio de um questionário para saber sobre sua produção.

Já outros $18 \%$ informaram que nunca receberam visitas das instituições. Talvez o motivo da ausência de tais instituições se deva ao fato de que algumas famílias não estão entre aquelas assistidas pelo Idam ou pela Prefeitura Municipal. 


\subsection{Participação na economia do município}

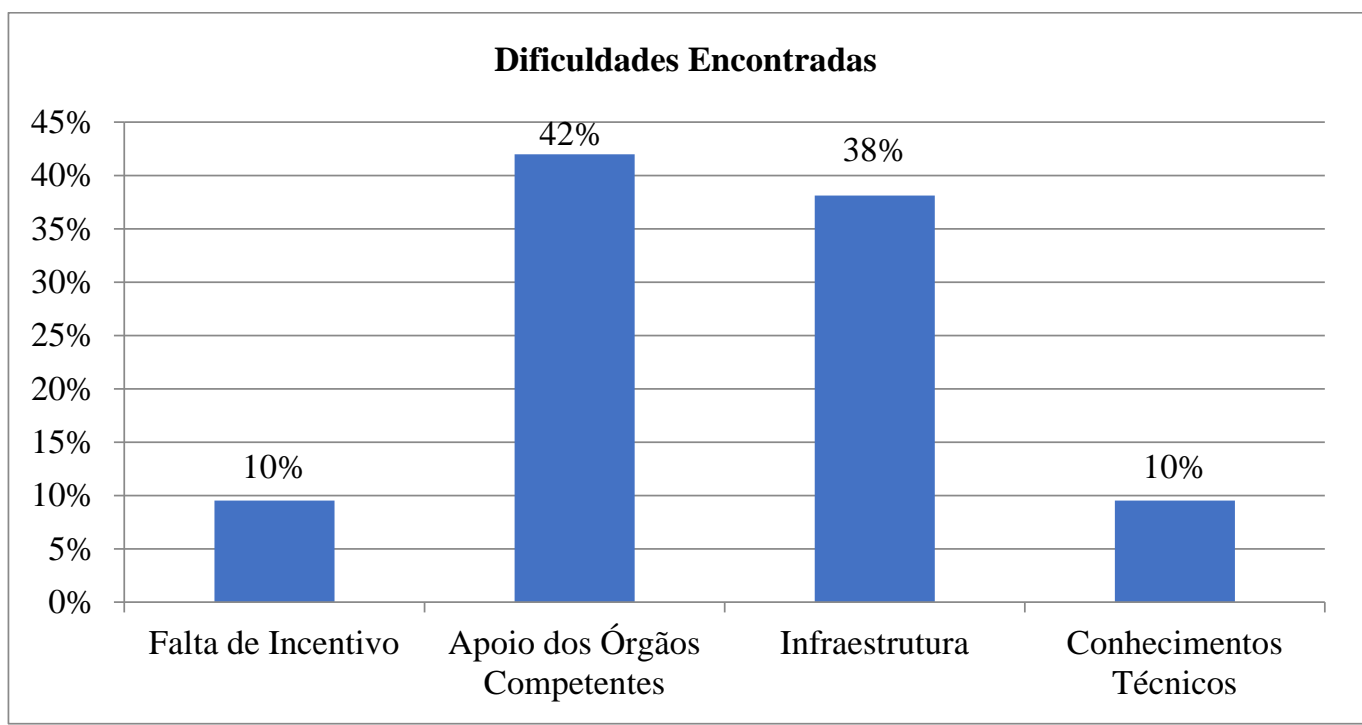

Gráfico 7 - Dificuldades encontradas para o estabelecimento do negócio familiar na AAR.

O Gráfico 7 mostra quais são os principais gargalos que dificultam o trabalho da Associação no que se refere ao seu desenvolvimento e estabelecimento efetivo no mercado local de seus produtos. Entre os vários fatores elencados que dificultam o desenvolvimento da agricultura familiar no município de Tabatinga encontra-se uma taxa de $42 \%$ que dizem que o apoio dos órgãos (Idam, Ifam, Sebrae) é fundamental para o seu desenvolvimento, seguido de $38 \%$ que dizem que a infraestrutura influencia bastante no momento em que o produto final vai para o consumidor, afetando sua renda no fim do mês. Por fim, com $10 \%$ cada um, encontra-se dificuldade na comunidade em razão da falta de incentivos e de conhecimentos técnicos.

Diante do exposto, segundo Azevedo, Colognese e Shikida (2000), diversos problemas interferem no êxito da agricultura familiar, existindo dificuldades relacionadas a produção, comercialização e financiamentos, além de dificuldades no transporte dos produtos produzidos na propriedade para o município até chegar ao consumidor. As dificuldades listadas acima podem ser sanadas; basta que os órgãos competentes prestem apoio a essa atividade para promover o seu desenvolvimento. Mas o que fica explícito é o descaso com a infraestrutura na zona rural bem como a falta de incentivo à agricultura familiar. E tais fatores apresentam-se como entraves ao desenvolvimento agrícola na comunidade Novo Horizonte. 


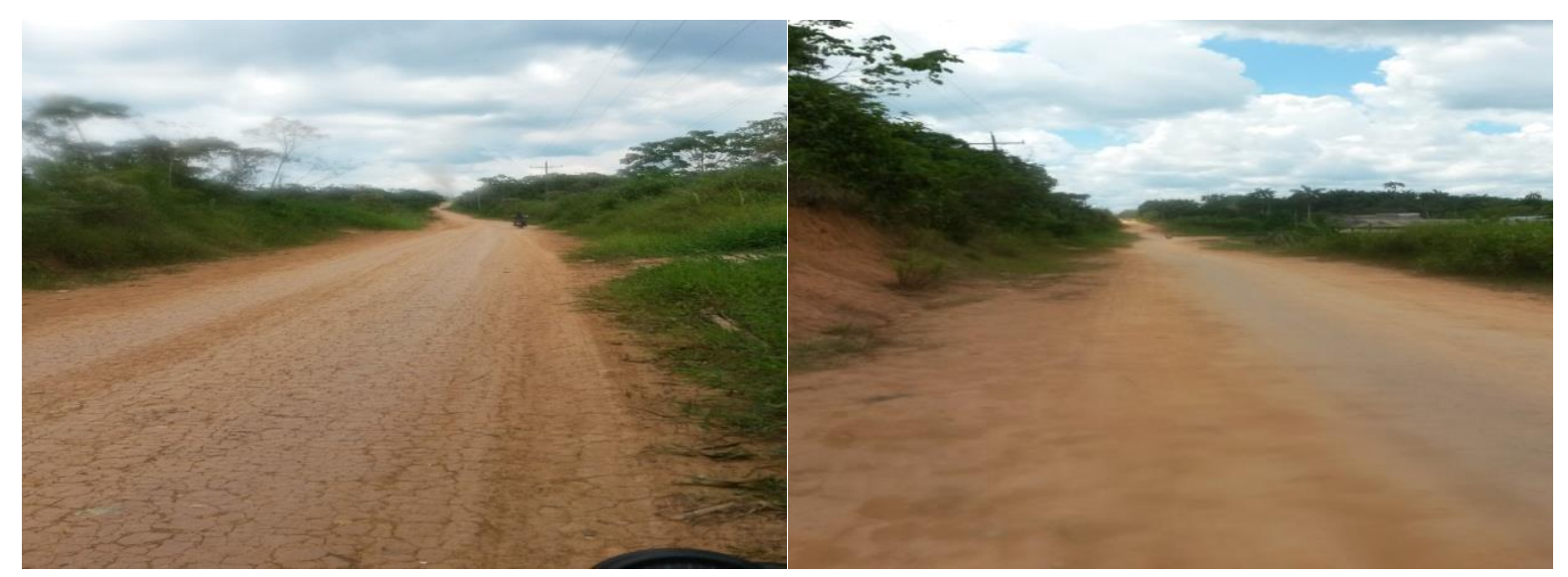

Imagem 1 - Estrada de acesso à zona rural do município e à Comunidade Novo Horizonte.

Embora as dificuldades possam configurar como um obstáculo para o desenvolvimento de sua atividade, a comunidade Novo Horizonte produz boa variedade de produtos e criação de animais para o autoconsumo e para as vendas. O Quadro 3 identifica os principais produtos que são produzidos pela comunidade. Os produtos são os mais diversos, tais como: macaxeira, tomate, cheiro verde, couve, repolho, pepino, alface, e frutas como banana, abacate, abacaxi, cupuaçu, limão, laranja, graviola, mamão, além da criação de animais como galinhas, ovelhas, perus, peixes, patos e porcos. Esses são os produtos mais cultivados na comunidade.

Quadro 3 - Produtos cultivados por famílias na AAR.

\begin{tabular}{|l|l|l|c|}
\hline $\mathbf{N}$ & Produto & Nome Científico & Número de Famílias Produtoras \\
\hline $\mathbf{1}$ & Macaxeira & Manihot esculenta Crantz & 10 \\
\hline $\mathbf{2}$ & Tomate & Lycopersicum Solanum & 3 \\
\hline $\mathbf{3}$ & Cheiro verde & Petroselinum crispum & 11 \\
\hline $\mathbf{4}$ & Couve & Brassica oleraceae sp. & 11 \\
\hline $\mathbf{5}$ & Repolho & B. oleracea L. var. capitata L. & 10 \\
\hline $\mathbf{6}$ & Pepino & Cucumis sativus. & 8 \\
\hline $\mathbf{7}$ & Alface & Lactura sativa sp. & 6 \\
\hline $\mathbf{8}$ & Banana & Musa spp. & 5 \\
\hline $\mathbf{9}$ & Abacate & Persea americana & 2 \\
\hline $\mathbf{1 0}$ & Abacaxi & Ananas comosus L. Merril & 4 \\
\hline $\mathbf{1 1}$ & Cupuaçu & Theobroma grandiflorum & 1 \\
\hline $\mathbf{1 2}$ & Limão & Citrus limon & 2 \\
\hline $\mathbf{1 3}$ & Laranja & Citrus sinensis L. Osbeck & 1 \\
\hline $\mathbf{1 4}$ & Graviola & Annona muricata L. & 1 \\
\hline $\mathbf{1 5}$ & Mamão & Carica papaya L. & 1 \\
\hline $\mathbf{1 6}$ & Criação de ovelhas & Ovis aries & 1 \\
\hline $\mathbf{1 7}$ & Criação de perus & Meleagris gallopavo & 1 \\
\hline $\mathbf{1 8}$ & Criação de peixes & Pseudopercis numida & 2 \\
\hline $\mathbf{1 9}$ & Criação de galinhas & Gallus spp. & 9 \\
\hline $\mathbf{2 0}$ & Criação de patos & Anas Platyrhynchos & 1 \\
\hline $\mathbf{2 1}$ & Criação de porcos & Sus scrofa & 1 \\
\hline & & & \\
\hline
\end{tabular}


Noda (2006) observa que a agricultura familiar no Amazonas é praticada em ambientes poucos modificados, que não sofreram, ainda, os impactos negativos do avanço da agropecuária estritamente voltada aos mercados ou das ações de projetos de desenvolvimento de grande porte voltados à exploração de recursos naturais. Sua produção é diversificada e, além de permitir oferta constante, ampla e variada de alimentos para o autoconsumo, proporciona maior estabilidade ao sistema produtivo, pois o suprimento das necessidades básicas em alimentos da família independe da comercialização; as crises do mercado podem afetar o núcleo produtivo, mas não inviabilizam sua sobrevivência.

Quadro 4 - Modo de realização das vendas dos produtos da Agricultura Familiar.

\begin{tabular}{|l|c|}
\hline Modo de Venda & $(\%)$ \\
\hline À porta & 5 \\
\hline Mercado Municipal & 37 \\
\hline Feira Sebrae & 37 \\
\hline Encomenda & 5 \\
\hline Atravessador & 5 \\
\hline Casa "Zona Urbana" & 11 \\
\hline
\end{tabular}

Para as famílias que realizam a venda de seus produtos, esse é um fator determinante para a fixação de sua renda no final do mês. Nesse ponto o Sebrae atua em parceria com a Associação, cedendo o espaço em frente à instalação física da Instituição aos sábados para que as famílias possam vender seus produtos em um lugar movimentado, podendo, assim, ter outro meio alternativo de comercializá-los e elevar sua renda. Com essa ação, uma taxa de $37 \%$ das famílias chega a vender no local, assim como outros $37 \%$ vendem seus produtos no mercado municipal de Tabatinga. A venda se dá também de porta em porta, por meio de encomendas e pelo atravessador, com um percentual de 5\% cada um. Os outros $11 \%$ vendem também em suas respectivas casas no município.

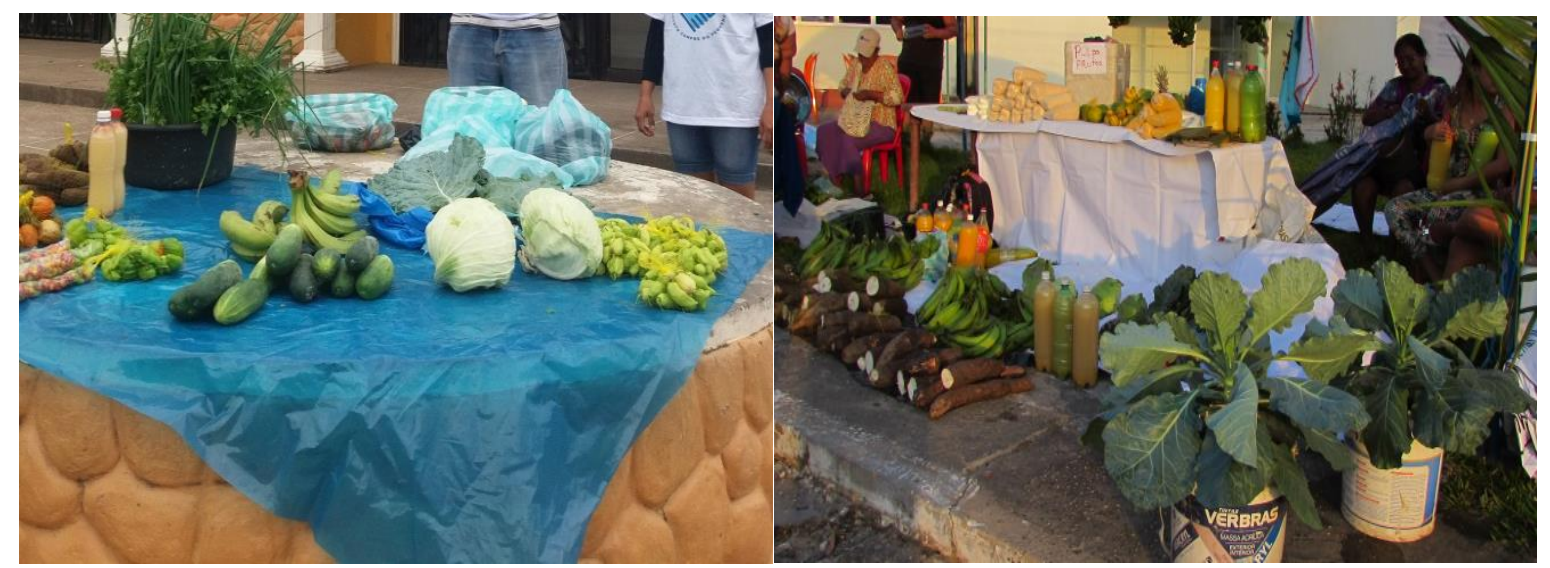

Imagem 2 - Feira Sebrae. 
Rodrigues, B. S., Simão, F. C. \& Petry, J. F. (2018).

A Imagem 2 mostra alguns dos produtos que as famílias agricultoras da AAR comercializam em frente ao Sebrae todos os sábados pela manhã.

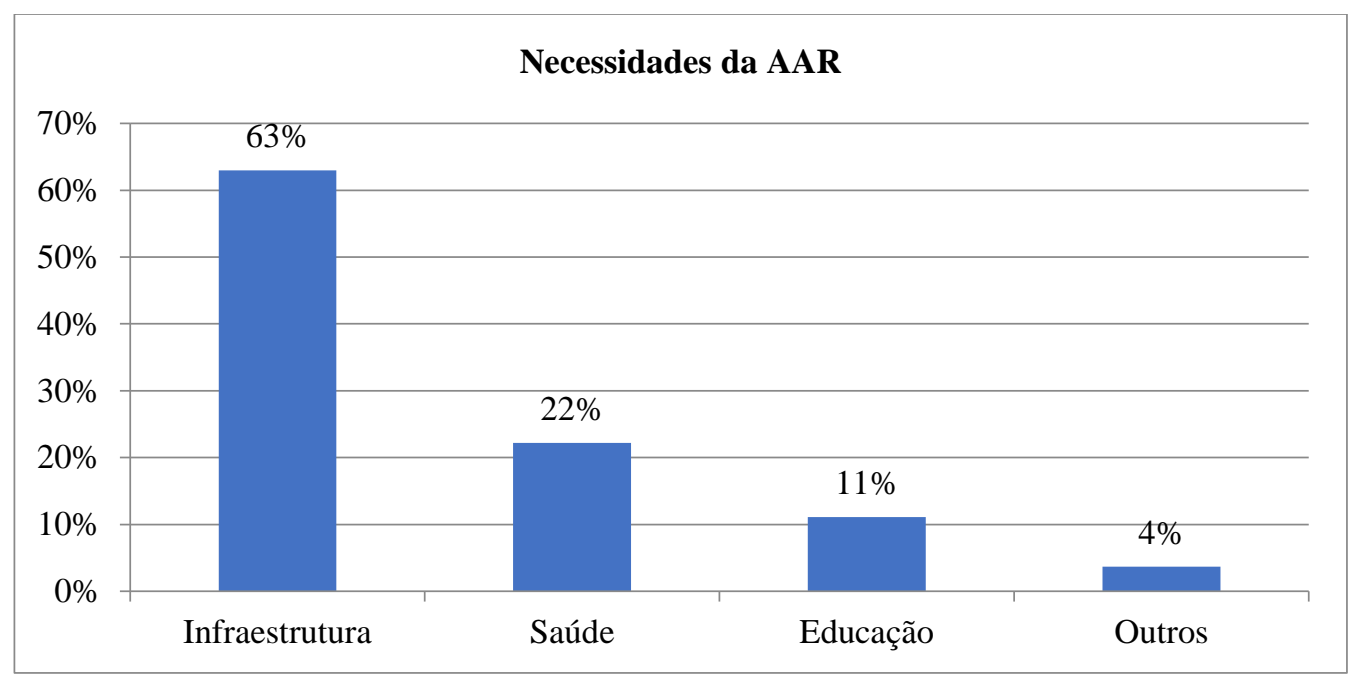

Gráfico 8 - Identificação das necessidades da AAR.

Quanto à identificação das necessidades da associação para alavancar suas atividades, constatou-se no Gráfico 8 que um percentual de 63\% aponta a precisão de melhorias na infraestrutura, o que indica a necessidade de pavimentação das estradas que dão acesso à zona rural do município. Esse percentual é seguido de $22 \%$ que indicaram a falta de investimento na saúde do campo, sendo então necessário criar postos de saúde próximos à comunidade. Outros $11 \%$ afirmam que necessitam de investimentos na área educacional, o que representa a criação de escolas na zona rural para que não haja deslocamento tão extensivo até a zona urbana. E apenas 4\% afirmam que a comunidade necessita de outros serviços, como segurança pública, devido a sua localização, já que está localizada em uma área distante da zona urbana, não havendo então ronda das viaturas e tampouco delegacias próximas, ficando vulneráveis.

Tais dificuldades enfrentadas diariamente podem ser resolvidas com o apoio dos órgãos públicos. Peters (1986) afirma que as políticas públicas são a soma das atividades dos governos que agem diretamente ou por meio de delegação e que influenciam a vida dos cidadãos. Desse modo, as ações que o governo vem tomando para o setor agropecuário influencia diretamente a comunidade, local do estudo, porém essa influência se dá de modo negativo, tendo em vista que as famílias agricultoras necessitam de apoio para que possam conseguir desenvolver-se.

Diante do exposto, fica evidente a afirmação de Abramovay (1998) quando diz que o agricultor familiar ainda tem de enfrentar velhos problemas, como a infraestrutura, nunca 
resolvidos, sendo ainda considerada uma atividade fragilizada. Com isso, é notório que o município deve tomar medidas para que possam melhorar as condições de vida na comunidade, beneficiando não somente a comunidade e os moradores de Novo Horizonte, mas também todos os agricultores e moradores das outras comunidades que estão localizadas no Projeto de Assentamento Urumutum.

\section{Considerações Finais}

O objetivo principal deste estudo é o de analisar os efeitos das políticas públicas na agricultura familiar num contexto peculiar do Brasil. Assim, percebe-se a importância das políticas públicas por meio da criação e aplicação dos programas de incentivo à agricultura familiar de modo a proporcionar melhorias na qualidade de vida dos agricultores assim como promover o desenvolvimento socioeconômico da comunidade como um todo. Com base nisso, é notável que as políticas públicas de fomento à agricultura familiar influenciam diretamente no modo que os agricultores vivem no campo. A pesquisa realizada na AAR possibilitou compreender a realidade, de modo a identificar alguns pontos críticos que necessitam ser transformados para melhorar o desempenho da Associação.

Primeiramente, destaca-se a ausência de liderança e gestão do presidente da AAR, pois identificou-se que não há uma influência pessoal, ou seja, o presidente não possui a habilidade de influenciar e conduzir as pessoas tendo em vista metas e objetivos que a Associação busca alcançar. Decorre disso a ausência da circulação de informação aos associados da AAR. O espírito de liderança é fundamental para fazer com que os associados se sintam motivados e encorajados pelo líder que têm, pois um líder é tido como aquele que consegue entender a vontade e o desejo da maioria e traduzi-la numa linguagem aceitável por todos para, a partir daí, conduzir o grupo à concretização desses desejos independentemente de sua própria vontade e interesse (Caetano, 2007).

As políticas públicas de fomento à agricultura familiar podem ser as mais diversas, como as citadas no embasamento teórico deste trabalho. Contudo, constatou-se na pesquisa que a associação não aderiu a nenhum dos programas citados, o que pode ser compreendido pela falta da obtenção da Declaração de Aptidão Jurídica (DAP), que é fornecida pelo Incra. Essa Declaração é necessária para obter financiamentos bem como para aderir aos programas ofertados, a exemplo do Pronaf. 
Rodrigues, B. S., Simão, F. C. \& Petry, J. F. (2018).

Outro aspecto importante identificado na pesquisa foi a falta de conhecimento dos associados em relação à oferta de Políticas Públicas de incentivo à agricultura familiar. Conforme demonstrado na análise dos resultados, a maioria desconhece os programas que o Governo Federal oferece para estimular as atividades agrícolas, fato este que também pode justificar o fato de a AAR não ser beneficiária de nenhum dos programas. Vale ressaltar que é dever da associação promover a formação dos associados para que possam contribuir eficazmente para o desenvolvimento de suas atividades.

Destaca-se também a dificuldade que os associados mostram em não apenas produzir e vender seus produtos, mas fazer com que seus produtos possam chegar ao cliente final com rapidez e com um preço mais competitivo. Isso ocorre devido ao péssimo acesso que há entre a zona urbana e a zona rural do município, considerando-se a falta de pavimentação das estradas, o que dificulta o translado dos moradores da comunidade Novo Horizonte para o município de Tabatinga, fazendo com que haja perdas na produção e na renda das famílias.

Com isso, é nítido que a agricultura de base familiar necessita de incentivos e investimentos do governo municipal e de outros órgãos competentes, mas isso não impede a sobrevivência das famílias que, apesar das necessidades e das dificuldades encontradas na comunidade, buscam meios de se adaptar aos fatores externos que dificultam o seu desenvolvimento.

A pesquisa também demonstrou quão importante é a participação de instituições como o Idam, o Ifam e o Sebrae no processo de aprendizagem dos associados. São parcerias importantes no que se refere à assistência técnica e ao cultivo de seus produtos, oferecendo suporte indispensável para a prática de suas atividades.

Nota-se também que, apesar de haver uma parceria entre os órgãos competentes e a comunidade, existe uma lacuna que necessita ser preenchida pelo governo municipal: as dificuldades encontradas pelos agricultores, como infraestrutura, educação, saúde e segurança pública; para promover o desenvolvimento dos agricultores rurais e proporcionar uma melhoria na qualidade de vida de todas as famílias da comunidade, é necessário que haja valorização e investimento do trabalho rural por parte da prefeitura municipal, que deve ajustar todos os problemas que dificultam a ampliação dessas atividades para beneficiar não somente a comunidade Novo Horizonte, mas todas as famílias que estão localizadas na zona rural de Tabatinga e que trabalham com a agricultura de base familiar.

Portanto, pode-se afirmar que, apesar de a Agricultura Familiar ter ganhado destaque ao longo dos anos enquanto sujeito do desenvolvimento, ainda está num processo de 
fortalecimento e valorização, que dependem de um conjunto de fatores econômicos, sociais, políticos e culturais. Desse modo, fica evidente que a AAR necessita promover a formação dos associados, discutindo essa necessidade em suas assembleias para que juntos possam decidir, por meio de propostas, as melhorias para o desenvolvimento dos associados com palestras e cursos específicos voltados para a sua área de atuação. Além disso, como fator fundamental para melhorias das atividades da AAR, deve-se buscar fortalecer as parcerias com as instituições que dão orientação e apoio técnico às famílias da comunidade, uma vez que estas são agentes essenciais para oferecer melhores condições na produção agrícola e assim poder aumentar a renda das famílias, bem como possibilitar mais oportunidades de empregos para a comunidade. Destaca-se, a parceria que o pesquisador pode ter com a AAR, pois está nítido que os associados bem como o presidente não possuem conhecimentos sobre liderança e gestão; então seria fundamental ministrar cursos e palestras sobre a temática para que ambos pudessem elevar seu grau de conhecimentos acerca do assunto, contribuindo, assim, para uma melhor formação tanto das pessoas quanto para o desenvolvimento da Associação.

$\mathrm{Na}$ prática, no entanto, este estudo contribui para a literatura existente sobre a importância das políticas públicas para a agricultura familiar. Os resultados assinalam, apesar dos esforços, a ausência, o apoio e o estímulo por parte de instituições para promover o desenvolvimento da agricultura familiar num contexto peculiar do Brasil, consequentemente, resultados subótimos de desenvolvimento. Os pressupostos teóricos estão altamente relacionados às contribuições empíricas, apesar de a assistência técnica estar presente na comunidade em discussão, carência na melhoria dos processos, baixa qualidade de vida e outras dificuldades relatadas, caracterizam a ineficiência da aplicabilidade das políticas de desenvolvimento na agricultura familiar. A investigação apresenta os seguintes achados principais que servem de contribuição para as políticas públicas, logo, uma atenção aos pressupostos das políticas de promoção da agricultura familiar, resulta numa melhora da qualidade de vida dos agricultores.

As implicações práticas para os decisores políticos visam promover a adoção de medidas urgentes tais como: em primeiro lugar, há uma forte evidência de baixo investimento na fomentação de políticas públicas para a promoção da agricultura familiar no interior do estado do Amazonas. Apesar de presentes algumas políticas de extensão, o foco e a qualificação desses profissionais precisam estar alinhados às políticas públicas de promoção a agricultura familiar. 
Rodrigues, B. S., Simão, F. C. \& Petry, J. F. (2018).

Em segundo lugar, as políticas de apoio e desenvolvimento agrícola no contexto do interior do estado do Amazonas são uma importante fonte de promoção e desenvolvimento de cidadania, gerando emprego e renda para as populações desassistidas.

Finalmente, o estudo revela que as políticas públicas de promoção e incentivo à agricultura familiar são relevantes, no entanto, o contexto específico em discussão, carece de manutenção e adaptação para a efetividade das políticas de promoção a agricultura familiar, tanto do poder público local, estadual ou nacional.

\section{Referências}

Abramovay, R. (1998). Agricultura familiar e desenvolvimento territorial. Reforma agrária, 28(1), 1-21.

Acevedo, C. R., \& Nohara, J. J. (2007). Monografia no curso de administração: guia completo de conteúdo e forma: inclui normas atualizadas da ABNT. São Paulo: Atlas.

Aked, J., Michaelson, J., \& Steuer, N. (2010). The role of local government in promoting wellbeing: Healthy Communities Programme. Local Government Improvement and Development.

Araújo, A., Canteri, M. H. G., Bittencout, J. M., \& Rodrigues, B. A. (2017). Contribution of the Brazilian government purchasing programs - PAA and PNAE - to strengthening family agriculture. Espacios, 38(9).

Azevedo, P. R., Colognese, S. A., \& Shikida, P. F. A. (2011). Agroindústrias familiares no Oeste do Paraná: um panorama preliminar. Organizações Rurais \& Agroindustriais, 2(1).

Cabral, L., Favareto, A., Mukwereza, L., \& Amanor, K. (2016). Brazil's agricultural politics in Africa: More food international and the disputed meanings of "family farming". World Development, 81, 47-60.

Caetano, R. M. (2007). Legitimidade da liderança no Ministério da Saúde - um ensaio. Revista do Serviço Público, 58(2), 181-211. 
Chamhuri, N. H., Hamdan, H., Ahmah, P., \& Ismail, F. (2015). Conceptual framework of public participation in ensuring quality of life of the urban poor in Malaysia. ProcediaSocial and Behavioral Sciences, 168, 349-356.

Collis, J., \& Hussey, R. (2005). Pesquisa em administração: um guia prático para alunos de graduação e pós-graduação. Porto Alegre: Bookman.

Cornwall, A., \& Brock, K. (2005). What do buzzwords do for development policy? A critical look at "participation","empowerment" and "poverty reduction". Third world quarterly, 26(7), 1043-1060.

Dye, T. D. (1984). Understanding public policy. Englewood Cliffs, N.J.: Prentice-Hall.

Freund, J. E., \& Simon, G. A. (2000). Estatística aplicada (9a ed.). Porto Alegre: Bookman.

Gil, A. C. (2007). Como elaborar projetos de pesquisa (4a ed.). São Paulo: Atlas.

Instituto Brasileiro de Geografia e Estatística - IBGE (2015). Diretoria de Pesquisas, Coordenação de População e Indicadores Sociais. Recuperado em 10 maio, 2017, de www.cidades.ibge.gov.br

Instituto de Desenvolvimento Agropecuário e Florestal Sustentável do Estado do Amazonas. (2016). Plano Operacional. Manaus: AM.

Lei n. 11.326, de 24 de julho de 2006 (2006). Diretrizes para a formulação da Política Nacional da Agricultura Familiar e Empreendimentos Familiares Rurais. Brasília-DF.

Lei n. 11.947, de 16 de junho de 2009 (2009). Atendimento da alimentação escolar e do Programa Dinheiro Direto na Escola aos alunos da educação básica e dá outras providências. Brasília-DF.

Lima, D. M. D. A., \& Wilkinson, J. (2002). Inovação nas tradições da agricultura familiar. Brasília: CNPq/Paralelo, 15.

Lynn, L. E. (1980). Designing public policy: A casebook on the role of policy analysis. Santa Monica, Calif.: Goodyear. 
Rodrigues, B. S., Simão, F. C. \& Petry, J. F. (2018).

Marconi, M. D. A., \& Lakatus, E. M. (2009). Fundamentos de metodologia científica (6a ed.). São Paulo: Atlas.

Mead, L. M. (1995). Public policy: vision, potential, limits. Policy Currents, 5(1), 1-4.

Ministério do Desenvolvimento Agrário (2013). Políticas públicas para agricultura familiar. Brasília: MDA.

Mohan, S. (2017). State of the state: politics of power shifts and shifting power of the state in India. Current Opinion in Environmental Sustainability, 24, 42-46.

Nehring, R., Miranda, A., \& Howe, A. (2017). Making the case for institutional demand: supporting smallholders through procurement and food assistance programmes. Global Food Security, 12, 96-102.

Noda, H. (2006). Agricultura familiar na Amazônia, segurança alimentar e agroecologia. Instituto Nacional de Pesquisas da Amazônia. Coordenação de Pesquisa em Ciências Agroeconômicas. Recuperado em 28 maio, 2017, de www2.emater.pa.gov.be/EmaterPortal/downloads/.../afriFamAmz.pdf

Oliveira, F. D. C., Collado, A. C., \& Leite, L. F. C. (2013). Autonomy and sustainability: An integrated analysis of the development of new approaches to agrosystem management in family-based farming in Carnaubais Territory, Piauí, Brazil. Agricultural systems, 115, 19.

Peters, B. G. (1986). American public policy. Chatham, N.J.: Chatham House.

Petrini, M. A., Rocha, J. V., Brown, J. C., \& Bispo, R. C. (2016). Using an analytic hierarchy process approach to prioritize public policies addressing family farming in Brazil. Land Use Policy, 51, 85-94.

Polit, D. F., Beck, C. T., \& Hungler, B. P. (2004). Fundamentos de pesquisa em enfermagem: métodos, avaliação e utilização (5a ed.). Porto Alegre: Artmed.

Stavropoulou, M., Holmes, R., \& Jones, N. (2017). Harnessing informal institutions to strengthen social protection for the rural poor. Global Food Security, 12, 73-79. 
Teixeira, E. C. (2002). Políticas públicas - O papel das políticas públicas. Salvador: AATR.

Triviños, A. N. S. (1987). Introdução à pesquisa em ciências sociais: a pesquisa qualitativa em educação. São Paulo: Atlas.

Van Vliet, J. A., Schut, A. G., Reidsma, P., Descheemaeker, K., Slingerland, M., Van de Ven, G. W., \& Giller, K. E. (2015). De-mystifying family farming: features, diversity and trends across the globe. Global Food Security, 5, 11-18. 